\title{
Smart Mobility: Services, Platforms and Ecosystems
}

\author{
Jukka Pulkkinen, Jari Jussila, Atte Partanen, Igor Trotskii, Aki Laiho
}

\author{
"If everyone is moving forward together, \\ then success takes care of itself." \\ Henry Ford, \\ Founder of Ford Motor Company
}

\begin{abstract}
In this study, we provide novel insight into building and managing growth in a new emerging market: the operation and maintenance of a heterogeneous and expanding vehicle fleet in a smart city environment. There are several different types of players in this emerging market and a dominant player is still missing. Based on our empirical findings, we identified three key characteristics of a growing business and the ability to reach a leading position: 1) co-creation through resource integration and service exchange is preferable for responding to market demands; 2) a digital platform is critical to create the necessary knowledge for resource integration and service exchange; and 3) smart services glue the ecosystem and platform together and create the outcome that solves the defined business problem. Most importantly, all three elements- ecosystem, platform and smart services- create a uniform environment in which to grow the business in a new emerging market.
\end{abstract}

\section{Introduction}

Smart mobility is booming and comprises an important part of the development of smart cities. City bikes are already widely used in many cities and new types of vehicles, such as scooters, are entering the market. This opens new niche markets for vehicle fleet operation and maintenance, and creates challenges for effective services, due to the existence of expanding heterogeneous vehicle fleets located in large geographical areas, and the inclusion of new types of vehicles with operation and maintenance requirements.

The market for smart mobility is increasing rapidly. Mobility as a service (MaaS) (Docherty, Marsden \& Anable, 2018) is becoming an increasingly popular model that is changing transportation chains for people in many cities (Loidl, Witzmann-Müller \& Zagel, 2019). This transportation disruption creates a new niche market for commercial actors operating and maintaining the whole vehicle fleet on behalf of a city. Currently, there are several different types of companies trying to gain a share in this market, starting from local small maintenance providers and ending with global technology companies that provide smart mobility systems, such as city bike systems. The winner in the new growing market will be the player who is capable of managing service operations at lower cost, while at the same time ensuring a sufficiently high quality for a fast-growing vehicle fleet (Pulkkinen, Jussila, Partanen \& Trotskii, 2019). Therefore, utilizing data to fulfil the above-mentioned requirements will be one critical success factor in achieving a significant market share. In current-day practice, there are several challenges in operating and managing an expanding vehicle fleet. Small local companies cannot easily expand to other cities, and big technology companies that deliver one type of smart mobility system, may encounter problems in operating and managing other vendors' systems, among other examples.

We draw on service-dominant (S-D) logic, defined as dynamic, continuing value co-creation through resource integration and service exchange, which has been constructed by an increasingly large number of academics (Lusch, Vargo \& Fisher, 2014; Vargo \& Lusch, 2017). "Resources", in this context, refers to broad knowledge and skills. S-D logic is moving toward a general theory of marketing and requires more midrange theoretical frameworks and practical use cases. One S-D logic diffusion is ecosystem services (Vargo \& Lusch, 2017). Business ecosystem development has been the focus of many researchers over recent decades (Järvi \& Kortelainen, 2017). The development of information and communications technology (ICT) has come to be seen as a cornerstone of the digital business ecosystem (DBE), in which a digital platform is used to create 


\section{Smart Mobility: Services, Platforms and Ecosystems}

Jukka Pulkkinen, Jari Jussila, Atte Partanen, Igor Trotskii, Aki Laiho

knowledge from data, and this knowledge is then utilized in business ecosystems (BEs) value co-creation (Senyo, Liu \& Effah, 2019). The ecosystem can either expand or shrink, depending on the decision-making and behaviour of all of the individual actors belonging to the ecosystem. Therefore, ecosystem dynamics has been the focus of several researchers (Senyo et al., 2019; Tsujimoto, Kajikawa, Tomita \& Matsumoto, 2018).

In the literature, there is a research gap relating to the operation and maintenance of smart mobility systems, due to the previous focus on developing ecosystems that connect users to smart mobility systems (Docherty et al., 2018; Faber, Rehm, Hernandez-Mendez \& Matthes, 2018; Ji, Cherry, Han \& Jordan, 2014; Loidl et al., 2019). On the other hand, empirical evidence on how to manage knowledge and the stability of BEs remains limited (Jacobides, Cennamo \& Gawer, 2018). Accordingly, this paper aims to address service development for commercial actors operating and maintaining vehicle fleets and to consider how the ecosystem should be utilized to gain a significant share in the new growing market. Building on existing research, we aim to answer the following research question: "What is the most effective way to build and manage a sustainable and expanding ecosystem for vehicle fleet operation and maintenance?" An ecosystem is presented in Fig. 1. The paper explores service business development that utilizes an ecosystem to improve the business' competitive position in a new market. Service business development creates artefacts to maintain and operate the expanding and heterogeneous vehicle fleet, in a way that enables the commercial actor to gain a significant market share. The results also present new practical guidelines generally to ecosystem actors for the creation of an expanding ecosystem, and some specific practical learning in this specific new market. As well, the results present one practical use case that more effectively bridges practice and theory in the area of ecosystem services, as one subdiscipline in S-D logic.

\section{Theoretical Background}

Smart Mobility

The development of a sharing economy is reshaping a

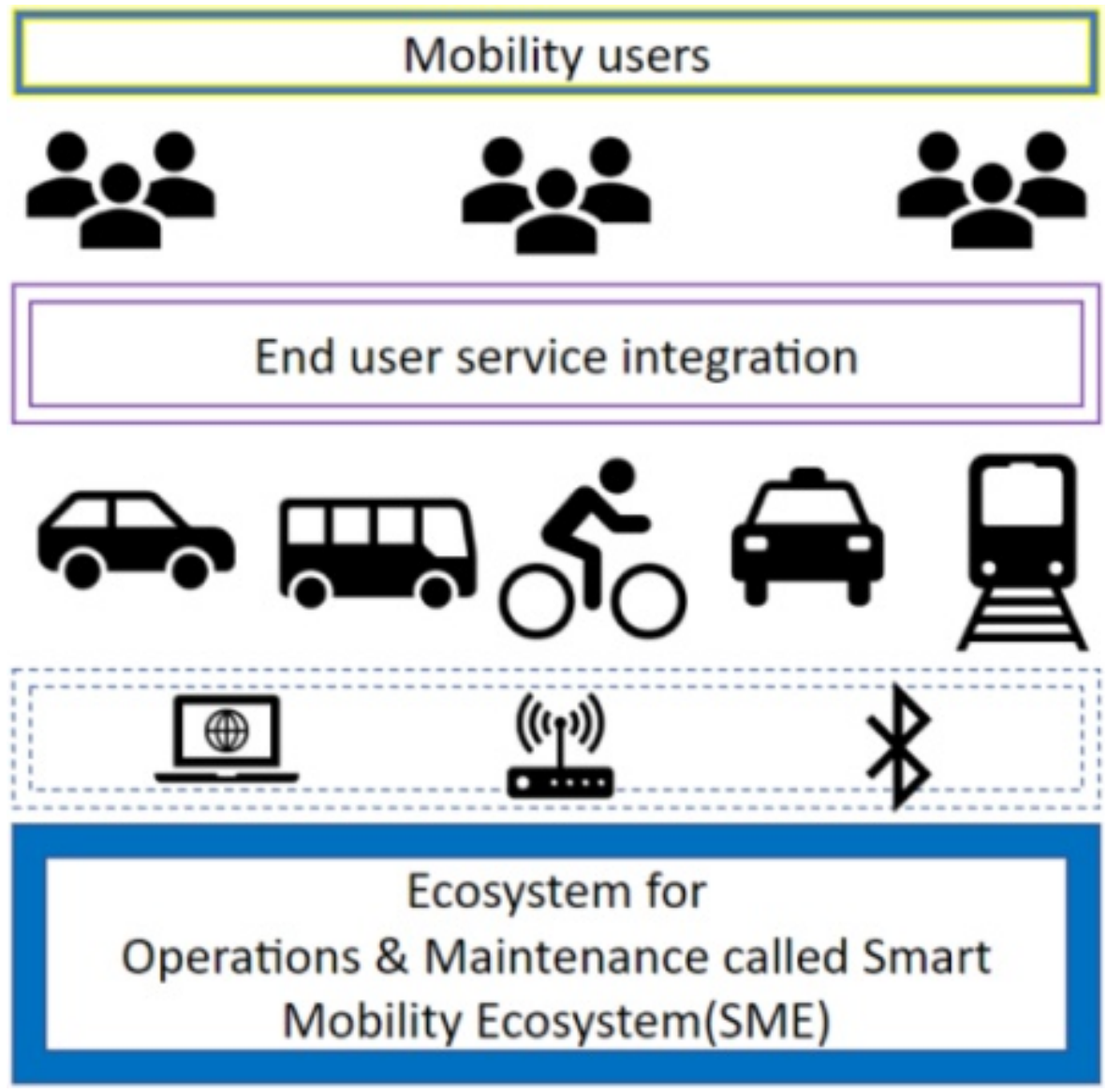

Figure 1. Smart Mobility Ecosystem to operate and maintain the vehicle fleet 


\section{Smart Mobility: Services, Platforms and Ecosystems Jukka Pulkkinen, Jari Jussila, Atte Partanen, Igor Trotskii, Aki Laiho}

large number of economic sectors, simultaneously offering new business opportunities and potentially disrupting traditional sectors (Acquier, Carbone \& Massé, 2019). New business models that utilize a sharing economy model in the mobility market have gained momentum in many cities (Hamari, Sjöklint \& Ukkonen, 2016; Yin, Qian \& Shen, 2018). One example of a sharing economy model is the so-called MaaS model, in which consumers do not own vehicles, but are provided with transport through a service provider. A bike-sharing system is another example of a sharing economy, and this system has experienced a tremendous boom in many cities (Loidl et al., 2019). Additional mobility solutions are expected to penetrate into markets. Already, the first shared electric scooters are in commercial use and drones have been piloted for package transport in Finland. Consequently, we can state that the market for different mobility solutions using a sharing economy model is growing rapidly.

Naturally, this opens up new business opportunities. One such opportunity is vehicle fleet operation and maintenance, since companies providing transport services do not always have the capability to operate and maintain their vehicle fleet effectively. The core competence for the transport service providers is different from that required for the technical operation and maintenance of the fleet. Consequently, there are companies focusing on this new niche market, providing vehicle fleet operation and maintenance. In the literature, there are several studies on managing mobility as part of a sharing economy for mobility users, along with methods of mobility system planning (Docherty et al., 2018; Faber et al., 2018; Ji et al., 2014; Loidl et al., 2019). On the other hand, there is a gap in the literature relating to the successful operation and maintenance of mobility systems. The operation and maintenance of a vehicle fleet fits well into the platform economy model, because there are consumers for the maintenance (vehicles) and providers of the maintenance (maintenance personnel).

\section{Digital Business Ecosystem}

The origin of the term "ecosystem" comes from biology. Tsujimoto et al. (2018) define it as "a biological system composed of all the organisms found in a particular physical environment, interacting with it and each other". Later it was also applied in business, in which a "business ecosystem" is an economic community of individuals and organizations, operating outside of their traditional industry boundaries (Moore, 1993; Senyo et al., 2019). According to Iansiti and Levien (2004), the three critical success factors in a business ecosystem are productivity, robustness and the ability to create niches and opportunities for new firms (Korpela, Kuusiholma, Taipale \& Hallikas, 2013).

Due to the emergence and exploitation of digital technology, new ways of co-creating value in the $\mathrm{BE}$ have been created. This has led to the development of the "digital business ecosystem" (DBE) concept, which combines the two main tiers of digital platforms and BEs, and is defined as a "sociotechnical environment of individuals, organizations and digital technologies with collaborative and comparative relationships, aiming to co-create value through shared digital platforms" (Senyo et al., 2019).

DBEs consist of different individuals and organizations known as actors. Typically, there are different types of actors with different goals for an ecosystem, and their different decision-making and behavioural principles are important for creating a sustainable DBE. This behaviour creates the dynamic of a DBE, which leads to either expansion or shrinkage of the system (Tsujimoto et al., 2018). If one actor has a strategic intention to design the whole ecosystem, then this actor is called the designing actor. The designing actor can manage the ecosystem strategically if the person or organization understands and manages the behaviour of the ecosystem dynamics (Tsujimoto et al., 2018).

The sustainability of restricted DBEs has been the focus of many studies. When the designing actors have tight control over other actors, the leader-follower relationship weakens the sustainability of the ecosystem (Joo \& Shin, 2018). On the other hand, there are different target goals for different actors, such as those relating to shared costs, shared risks, increases in flexibility, etc. (Graça \& Camarinha-Matos, 2017). In a collaborative DBE, where the behaviour and decisionmaking of different actors fits naturally into a common goal, the ecosystem behaviour is coherent, supporting the sustainability and expansion of the system (Tsujimoto et al., 2018). The customers in this ecosystem are also actors and their participation varies according to business characteristics (Joo \& Shin, 2018). The digital platform is used to create and share knowledge in the ecosystem. The interoperability of data and knowledge among all actors is therefore critical for a sustainable DBE (Figay, Ghodous, Khalfallah \& Barhamgi, 2012; Selma et al., 2012; Vernadat, 2009). Finally, we can state that a sustainable and expanding DBE must have a collaboration target as a common output of the whole ecosystem, and the individual behaviour and decision-making of all actors must be aligned with that collaboration target. The designing actor has a leading role in managing the 


\section{Smart Mobility: Services, Platforms and Ecosystems}

Jukka Pulkkinen, Jari Jussila, Atte Partanen, Igor Trotskii, Aki Laiho

dynamics of the ecosystem to ensure that the behaviour of all actors supports a coherent ecosystem.

\section{Service Ecosystem}

S-D logic represents dynamic value co-creation through resource integration and service exchange. This has attracted a great deal of attention from a large number of academics from various disciplines (Vargo \& Lusch, 2017). "Resources" refers to the broad knowledge and skills used to create a benefit. This conceptualization of a service using S-D logic reflects resource integration for the creation of value through a network with a common purpose, rather than only connections of resources, people or product flows. This approach shifts the focus from the firm-centric production of outputs, to activities and processes in which different actors' resources are integrated to reach their common collaboration target (KetonenOksi \& Valkokari, 2019; Wieland, Hartmann \& Vargo, 2017).

The development of ICT enables new models for cooperation in the design, production, delivery and consumption of services (Anttiroiko, Valkama \& Bailey, 2014). Organizations are increasingly digitally connected to each other, leading to the construction of digital ecosystems that form the basis for new service ecosystems and BEs (Nachira, Dini \& Nicolai, 2007).
One area of smart services concerns mediating the roles between providers and end customers of a service ecosystem. Digitally connected resources and organizations boost this development (Alt, Demirkan, Ehmke, Moen \& Winter, 2019).

The conceptual exploration of service ecosystems has just begun, and evidence-gathering and real applications are needed to deepen the understanding of these ecosystems in different circumstances (Vargo \& Lusch, 2017).

\section{Methodology}

This research aims to develop new services by creating artefacts as a solution to an unsolved business problem. As well, it uses the developed new services as the use case in a coherent ecosystem, to define the guidelines needed to create a sustainable and growing ecosystem. The research strategy was thus, quite naturally, to use design science, in which interests are critical and emancipatory, with a practical orientation. Design science seeks to extend the boundaries of human and social capabilities, i.e., knowledge and skills, by creating new and innovative artefacts (Hevner, Chatterjee, Park \& Ram, 2004). The most important criteria for wellconducted design science research include the requirements that an artefact is created to address a

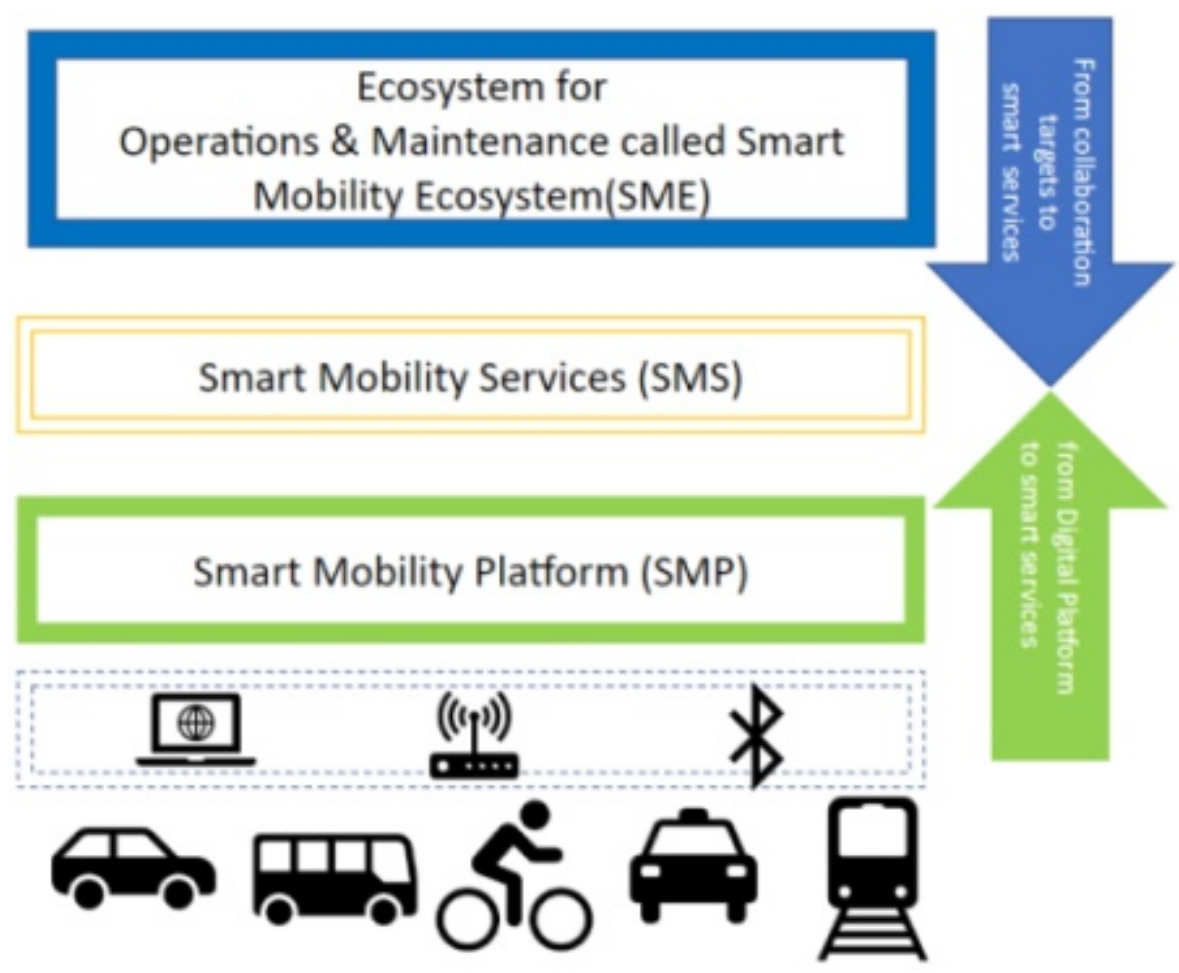

Figure 2. The Artifacts: Smart Mobility Ecosystem, Smart Mobility Services and Smart Mobility Platform 


\section{Smart Mobility: Services, Platforms and Ecosystems}

\section{Jukka Pulkkinen, Jari Jussila, Atte Partanen, Igor Trotskii, Aki Laiho}

problem, should be relevant to the solution of an unsolved and important business problem, and that research should present a verifiable contribution, with rigour applied both in the development and evaluation of the artefact (Peffers, Tuunanen, Rothenberger \& Chatterjee, 2007).

The relevance and importance of the business problem is opportune, as smart mobility is currently booming in Finland. Bike-sharing systems are already in use in the capital region (Helsinki), and in the cities of Turku and Kuopio. A new, full-scale system is coming to the city of Oulu. A bike-sharing pilot scheme for research purposes is starting in the city of Hämeenlinna (Ruohomaa \& Salminen, 2019). Additionally, an electric scooter-sharing system is already in use in Helsinki. On the other hand, all sharing systems require certain infrastructure, such as stations and ticket machines, to run the overall system. All of the vehicles and the infrastructure must be maintained, creating a growing market for the operation and maintenance of these systems.
In order to determine the answer to the research question, a more detailed objective was defined. This was done in collaboration with commercial actors operating and maintaining a vehicle fleet of more than 2,000 vehicles and other infrastructure equipment in 19 cities. The objective was to find a new way of providing services that is more efficient, easy to expand, fulfils defined quality requirements, and utilizes knowledge created by a digital platform. A data strategy framework (Pulkkinen et al., 2019) was rigorously utilized to develop a new way of providing services. The development of new services resulted in three new artefacts: a Smart Mobility Ecosystem (SME), a Smart Mobility Platform (SMP) and Smart Mobility Services (SMS) as described in Fig. 2. SMP functionalities were subjected to technical testing and a few iterations were made to develop the final functionalities. This process resulted in the structure of the SMP presented in Fig. 3, and in general requirements for the SMP. Following a design science methodology (Peffers et al., 2007), we also present a more general theoretical framework for smart services in a DBE environment.
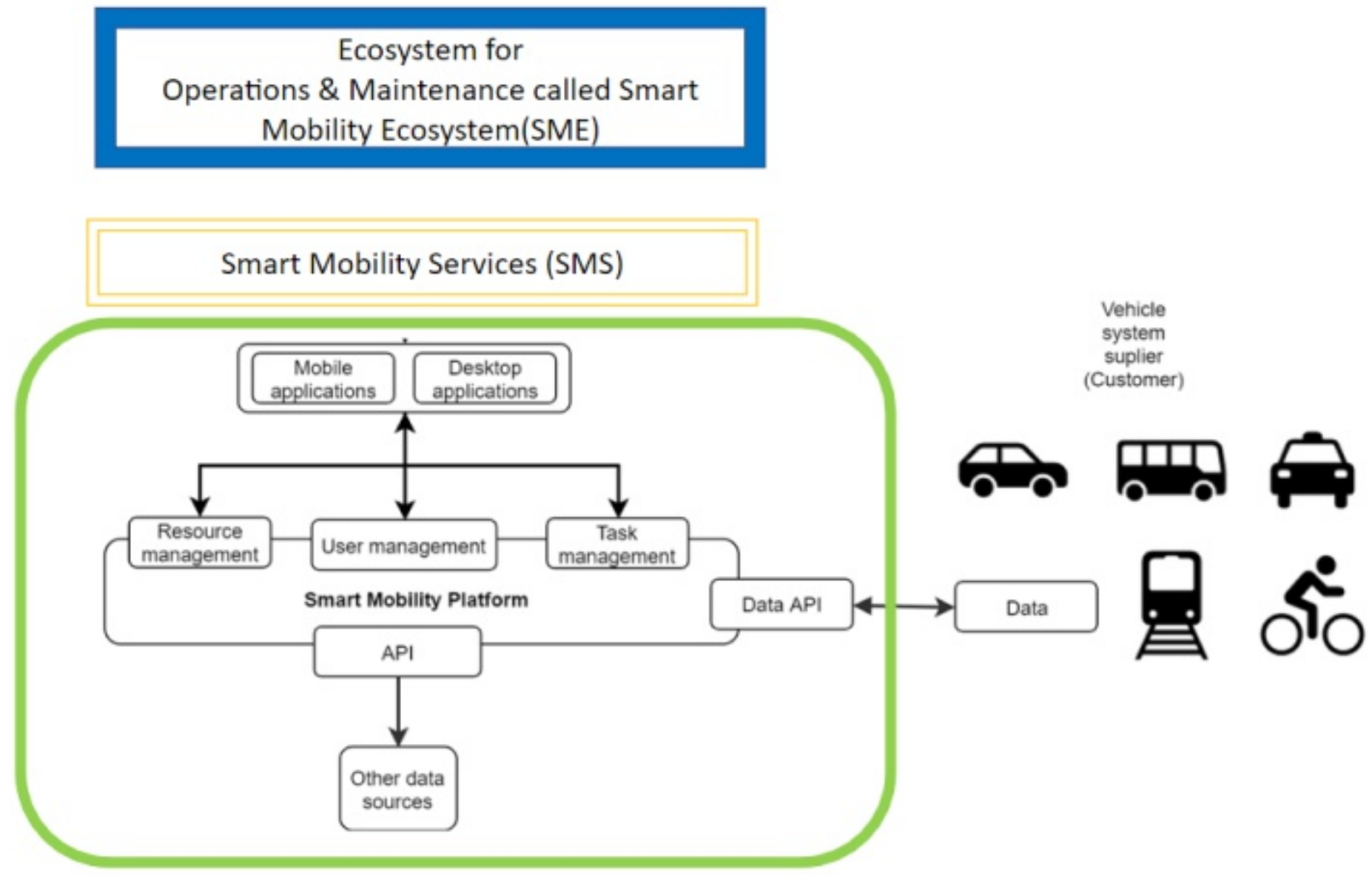

Figure 3. Smart Services needs to reach the collaboration targets by utilizing the knowledge created from data 


\section{Smart Mobility: Services, Platforms and Ecosystems \\ Jukka Pulkkinen, Jari Jussila, Atte Partanen, Igor Trotskii, Aki Laiho}

\section{Evaluation}

The evaluation was performed to ensure that the developed artefacts fulfil the defined objective, which was to develop a new way of providing services that is more efficient, easy to expand and fulfils defined quality requirements. In practice, the evaluation was performed in workshops, where researchers and personnel from a commercial company verified the services. Personnel from the company have extensive experience in providing operation and maintenance services for different types of vehicle systems. A new method of providing services utilizing the SMP was also tested by researchers and maintenance personnel, using the idea of a "proof of concept" in the field. Additionally, the roadmap to create the SME was rigorously discussed and analysed by the senior management of the commercial actors.

\section{Results}

The development of new services that fulfil the defined objective above, resulted in three new artefacts: the SME, SMP and SMS. The next objective was to find a new, more efficient and easy way to expand provision of services that fulfil the defined quality requirements, and which utilize knowledge created by the SMP.

\section{Smart Mobility Ecosystem}

A sustainable and expanding SME requires a leading company, which is the designing actor in a bounded or restricted ecosystem. The designing actor needs to create a coherent ecosystem in which the behaviour of all actors is aligned with their collaboration target. In this case, the designing actor is a commercial actor operating and maintaining the vehicle fleet. Other actors include the customer, the local maintenance providers, the vehicle system suppliers, and the consumers.

For the creation of a coherent SME by the designing actor, the following design criteria must be fulfilled by each actor.

The customer is typically the city owning the vehicle system. The customer defines the service scope and quality requirements in the service level agreement (SLA), and selects an operation and maintenance provider through competitive bidding. Accordingly, the customer's requirement with regard to the collaboration target is for services which fulfil the SLA requirements at the lowest price.
The designing actor must have the capability to operate and maintain a heterogeneous vehicle fleet over a geographically large area. The service scope and quality requirements are defined in the SLA separately by each customer and will vary, which increases the complexity. The collaboration targets services that fulfil the SLA requirements, at a cost level that represents the lowest price in competitive bidding, repeatedly, in order to gain a significant market share.

The local maintenance providers typically have first priority to directly service their customer, who will typically be in the same city. They may have some advantages such as local knowledge and relationships, but their capability to scale up operations to new types of vehicle, and especially to expand to new locations is limited. This makes their chances of growing to become a major player relatively small. Should they lose the contract to the designing actor, they may become a subcontractor to the designing actor and in this way, they become a member of the ecosystem and therefore the SMP is available to support their local operation. The basis of a coherent SME is a service operation that is effective enough to be competitive with regard to cost while simultaneously fulfilling the SLA's scope and quality requirements, with the help of the SMP. This defines the high technical requirements for an SMP and is a mandatory requirement for creating a coherent SME. If the SLA requirement is not fulfilled via costcompetitive service operation in the SME with the help of the SMP, the local maintenance provider has a good chance of making a contract directly with the customer, without the SME. The local maintenance provider's collaboration target is to provide local services as defined in the SLA by utilizing knowledge created by the SMP.

The vehicle system supplier must ensure the integration of the vehicle system and the SMP. It is important to have all the required data in the SMP, in order to manage the service operation and maintenance, as defined above. The vehicle system supplier's collaboration target is to provide an application program interface (API), that includes all of the data needed to optimize the operation and maintenance available to be connected to the SMP.

The consumers use the vehicle system and the quality of the system represents their expectations with regard to the collaboration targets. Vehicle systems that do not fulfil their quality requirements will have a low usage level, and ultimately, the SME will decline. In practice, this means that all vehicles must be in good condition to 


\section{Smart Mobility: Services, Platforms and Ecosystems \\ Jukka Pulkkinen, Jari Jussila, Atte Partanen, Igor Trotskii, Aki Laiho}

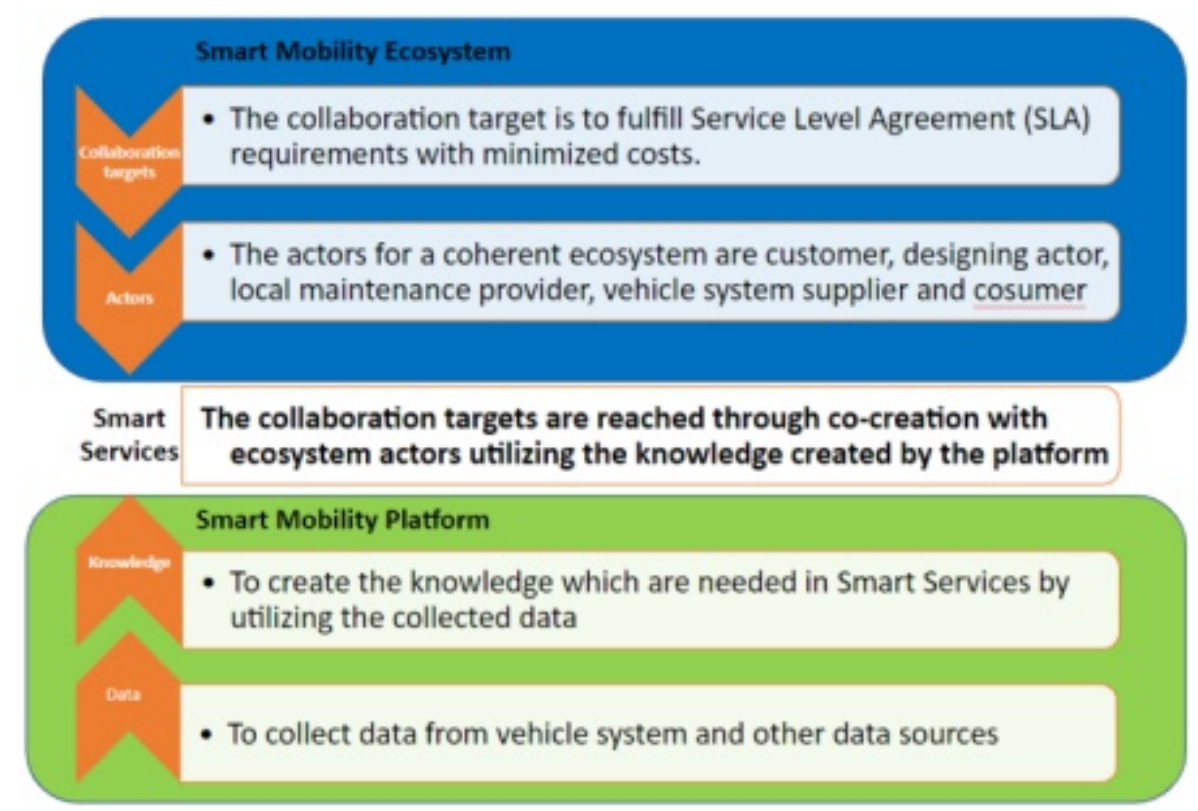

Figure 4. Smart Services needs to reach the collaboration targets by utilizing the knowledge created from data

drive, available when needed by consumers, and that there must be a place to easily leave vehicles after usage. Accordingly, the consumers' quality requirements need to be included in sufficient detail in the SLA requirements, which is the basis of the collaboration target for the SME.

\section{Smart Mobility Platform}

The SMP must provide a common application for the operation and maintenance of the vehicle fleet, as shown in Fig. 3. It defines the interactions of various actors within the SME and provides common interfaces for interacting in a well-defined way with the platform. The SMP must be capable of extending its functionality, as well as being easily integrated with other applications.

Based on the SMP's characteristics and functionality, general requirements were formulated. The provided requirements do not cover all the possible scenarios or required features, but they provide a solid guideline to follow, which considerably improves the probability of creating a coherent SME. On the other side, it also simplifies the design and life-cycle management of the systems.

1. The SMP must be highly modular. This means that different parts of the platform must be completely independent of each other. For example, the user interface for maintenance personnel must be independent of the platform's core logic. This requirement guarantees the ease of deployment and integration of the system, and increases its adaptability.

2. The SMP must provide well-documented and consistent APIs, both for integrating different internal modules into a single application and for connecting to external services. This requirement is essentially an extension of the first requirement.

3. The SMP must provide methods for automatic task generation, management and assignment to proper maintenance teams, based on the current state of the vehicle fleet. This requirement drastically increases the efficiency of operation and maintenance, and helps to ensure that the provided services fulfil the SLA requirements. This relies heavily on data collected from the vehicles and requirements defined by the SLA.

4. The SMP must provide all relevant information about maintenance tasks and the state of the vehicle fleet, and should be utilized for reporting.

5. The SMP must provide dedicated user interfaces for different actors.

6. The SMP must define and provide a common interface for easy extension of the platform to cover new types of vehicles.

\section{Smart Mobility Services}

The anchoring point in answering our research question: "What is the best way to build and manage a sustainable and expanding ecosystem for the vehicle fleet operation and maintenance?", relates to the SMS 


\section{Smart Mobility: Services, Platforms and Ecosystems Jukka Pulkkinen, Jari Jussila, Atte Partanen, Igor Trotskii, Aki Laiho}

that glue the ecosystem and platform together, and create the ecosystem outcome. SMS have built a new method of providing services for vehicle fleet operation and maintenance that is needed to fulfil the defined targets of greater efficiency and easier expansion meet the quality requirements, and utilize the knowledge created by the SMP.

In this new way of providing services, the actors' resources are applied so that the ecosystem is successful, expanding, and sustainable in the long run. This is called a coherent ecosystem. In practice, it means that the smart services outcome fulfils the collaboration targets by utilizing the unique knowledge created by the platform, as described in Fig. 4 . Accordingly, smart services can be defined so that the collaboration targets are reached through co-creation with ecosystem actors utilizing the knowledge created by the platform.

\section{Discussion}

The smart mobility market is a typical example of a relatively young industry which is growing fast. This means that there are relatively young companies in the industry, and tjat many are still in the start-up phase, waiting to penetrate the market. The leading vehicle system suppliers are not focusing on service business, but are instead giving full attention to the delivery of their smart mobility systems as a response to the growing demand. The service market is still very young and there is not yet any dominant player in the global market.

Based on our research, the biggest challenge in the creation of an SME is the integration of different vehicles on the SMP. This means that the vehicle system suppliers do not have API interfaces with all of the necessary data for vehicle operation and maintenance. In fact, they often have API interfaces, but these interfaces support only the connection of consumers to the system. Without an SMP that can connect and integrate data from different vehicle system suppliers, it will remain difficult to develop a robust (Iansiti \& Levien, 2004) and sustainable (Figay et al., 2012) SME.

The further development of this industry will be interesting. The importance of effective operation and maintenance will grow when the industry becomes more mature and undoubtedly, the vehicle system suppliers' interests in new services will increase in the future, as has been the case in many other industries. Obviously, the player who creates the first SMP and coherent ecosystem on top of the platform, will come to occupy the dominant position in this fast-growing service market. A real roadmap to building a SME is still missing, because the vehicle system suppliers' data is mandatory, and their interest in opening this type of interface is not yet in place. How this will be solved is not yet clear, but it is likely that cities, just like customers, could have some role to play, by requiring these interfaces early in the bidding phase of new smart mobility systems. In this way, the vehicle system suppliers would need to open their interfaces to the community of users.

Smart services as defined in this paper represent a dynamic, continuing narrative of value co-creation through resource integration and service exchange. Accordingly, this paper provides one use case using S-D logic in a real world scenario. Our research has presented concrete guidelines to create a coherent ecosystem in one specific industry and identified practical problems that need to be solved in order to obtain a major benefit from the ecosystem.

\section{Conclusion}

A new approach to services was presented with regard to the operation and maintenance of a heterogeneous and expanding vehicle fleet, in the new booming smart mobility market. The new method of providing services consists of an SME and an SMP, connected through SMS to co-create value for ecosystem customers.

A coherent SME, where the decision-making and behaviour of all actors supports the common collaboration targets is sustainable and can expand. The ecosystem is restricted and one actor in particular has a strategic intention to ensure its development; the commercial actor operating and maintaining the whole vehicle fleet. Other actors in the ecosystem comprise the local maintenance providers, vehicle system suppliers, customers, and consumers. In this article, the requirements were presented from each actor's point of view in order to create a coherent, sustainable and expanding ecosystem in the smart mobility environment. Empirical evidence from one case was presented regarding how designing actors can manage knowledge creation and sustainability of the ecosystem. Another result was the identification of technical requirements for the SMP as a basis for the sustainable and expanding ecosystem, thus ensuring a coherent ecosystem from the platform perspective.

Technical integration of different types of vehicles 


\section{Smart Mobility: Services, Platforms and Ecosystems}

Jukka Pulkkinen, Jari Jussila, Atte Partanen, Igor Trotskii, Aki Laiho

within a SMP is first needed to build a coherent ecosystem. Currently, vehicle system suppliers are not yet ready to open the required interfaces. Therefore further development is required to enable the full benefit from the above defined smart services to be obtained. On the other hand, the smart mobility market is currently developing at a rapid pace, and it will be interesting to discover who will succeed in creating a new ecosystem first and how this will be achieved.

\section{References}

Acquier, A., Carbone, V. \& Massé, D. 2019. How to Create Value (s) in the Sharing Economy: Business Models, Scalability, and Sustainability. Technology Innovation Management Review, 9(2). https://timreview.ca/article/1215.

Alt, R., Demirkan, H., Ehmke, J. F., Moen, A. \& Winter, A. 2019. Smart services: The move to customer orientation. Electronic Markets, 29(1): 1-6.

Anttiroiko, A.-V., Valkama, P. \& Bailey, S. J. 2014. Smart cities in the new service economy: building platforms for smart services. AI \& SOCIETY, 29(3): 323-334.

Docherty, I., Marsden, G. \& Anable, J. 2018. The governance of smart mobility. Transportation Research Part A: Policy and Practice, 115: 114-125.

Faber, A., Rehm, S. V., Hernandez-Mendez, A. \& Matthes, F. 2018. Modeling and visualizing smart city mobility business ecosystems: Insights from a case study. Information (Switzerland), 9(11).

https://doi.org/10.3390/info9110270.

Figay, N., Ghodous, P., Khalfallah, M. \& Barhamgi, M. 2012. Interoperability framework for dynamic manufacturing networks. Computers in Industry, 63(8): 749-755.

Graç, P. \& Camarinha-Matos, L. M. 2017. Performance indicators for collaborative business ecosystems Literature review and trends. Technological Forecasting and Social Change, 116: 237-255.

Hamari, J., Sjöklint, M. \& Ukkonen, A. 2016. The sharing economy: Why people participate in collaborative consumption. Journal of the Association for Information Science and Technology, 67(9): 2047-2059.

Hevner, A., Chatterjee, S., Park, J. \& Ram, S. 2004. Design Science Research in Information Systems. MIS Quarterly, 28(1): 75-105.

Iansiti, M. \& Levien, R. 2004. The keystone advantage: what the new dynamics of business ecosystems mean for strategy, innovation, and sustainability. Harvard Business School Press.

Jacobides, M. G., Cennamo, C. \& Gawer, A. 2018. Towards a theory of ecosystems. Strategic Management Journal, 39(8): 2255-2276.

Järvi, K. \& Kortelainen, S. 2017. Taking stock of empirical research on business ecosystems: a literature review. International Journal of Business and Systems Research, 11(3): 215-228.

Ji, S., Cherry, C. R., Han, L. D. \& Jordan, D. A. 2014. Electric bike sharing: Simulation of user demand and system availability. Journal of Cleaner Production, 85: 250-257.

Joo, J. \& Shin, M. M. 2018. Building sustainable business ecosystems through customer participation: A lesson from South Korean cases. Asia Pacific Management Review, 23(1): 1-11.

Ketonen-Oksi, S. \& Valkokari, K. 2019. Innovation Ecosystems as Structures for Value Co-Creation. Technology Innovation Management Review, 9(2). https://timreview.ca/article/1216.

Korpela, K., Kuusiholma, U., Taipale, O. \& Hallikas, J. 2013. A framework for exploring digital business ecosystems. 46th Hawaii International Conference on System Sciences, 3838-3847. IEEE.

Loidl, M., Witzmann-Müller, U. \& Zagel, B. 2019. A spatial framework for planning station-based bike sharing systems. European Transport Research Review, 11(1).

https://doi.org/10.1186/s12544-019-0347-7.

Lusch, R. F., Vargo, S. L. \& Fisher, R. 2014. Drawing on service-dominant logic to expand the frontier of physical distribution and logistics management. International Journal of Physical Distribution \& Logistics Management, 44(1/2): IJPDLM-07-20130209.

Moore, J. 1993. Predators and prey: a new ecology of competition. Harvard Business Review, 71(3): 75-86.

Nachira, F., Dini, P. \& Nicolai, A. 2007. A network of digital business ecosystems for Europe: roots, processes and perspectives. Introductory Paper. Bruxelles.

http://www.digitalecosystems.org/book/pdf/0.3.pdf.

Peffers, K., Tuunanen, T., Rothenberger, M. A. \& Chatterjee, S. 2007. A Design Science Research Methodology for Information Systems Research. Journal of Management Information Systems, 24(3): $45-77$.

Pulkkinen, J., Jussila, J., Partanen, A. \& Trotskii, I. 2019. Data strategy framework in servitization: Case study of service development for a vehicle fleet. Springer Proceedings in Complexity.

Ruohomaa, H. J. \& Salminen, V. K. 2019. Mobility as a service in smart cities - new concept for smart mobility in Industry 4.0 framework. ISPIM Ottawa Connects, Conference Proceedings, (April): 1-12.

Selma, K., Ilyès, B., Ladjel, B., Eric, S., Stéphane, J. et al. 2012. Ontology-based structured web data warehouses for sustainable interoperability: Requirement modeling, design methodology and tool. Computers in Industry, 63(8): 799-812.

Senyo, P. K., Liu, K. \& Effah, J. 2019. Digital business ecosystem: Literature review and a framework for future research. International Journal of Information 


\section{Smart Mobility: Services, Platforms and Ecosystems}

\section{Jukka Pulkkinen, Jari Jussila, Atte Partanen, Igor Trotskii, Aki Laiho}

Management, 47(June 2018): 52-64.

Tsujimoto, M., Kajikawa, Y., Tomita, J. \& Matsumoto, Y. 2018. A review of the ecosystem concept - Towards coherent ecosystem design. Technological Forecasting and Social Change, 136(June 2017): 49-58.

Vargo, S. L. \& Lusch, R. F. 2017. Service-dominant logic 2025. International Journal of Research in Marketing, 34(1): 46-67.

Vernadat, F. B. 2009. Technical, semantic and organizational issues of enterprise interoperability and networking. IFAC Proceedings Volumes (IFACPapersOnline), 13(PART 1): 728-733.

Wieland, H., Hartmann, N. N. \& Vargo, S. L. 2017. Business models as service strategy. Journal of the Academy of Marketing Science, 45(6): 925-943.

Yin, J., Qian, L. \& Shen, J. 2018. From value co-creation to value co-destruction? The case of dockless bike sharing in China. Transportation Research Part D: Transport and Environment.

https://doi.org/10.1016/j.trd.2018.12.004.
Citation: Pulkkinen, J., Jussila, J., Partanen, A., Trotskii,

I., Laiho, A. 2019. Smart Mobility: Services, Platforms

and Ecosystems. Technology Innovation Management

Review, 9(9): 15-24.

http://doi.org/10.22215/timreview/1265

(cc) BY

Keywords: Smart Mobility, Smart Services, Digital Business Ecosystems, Digital Platforms.

\section{About the Authors}

Dr. Jukka Pulkkinen holds a PhD degree in control engineering from Helsinki University of Technology. Currently, he acts as a principal research scientist at Häme University of Applied Sciences (HAMK). His research is currently focused on strategic business management, digital servitization and service development, especially in industry and smart city environments. Before his academic career, he had a long career in various leadership positions in a global industrial company, leading the service business, the EMEA sales region and a global business unit.

Dr. Jari Jussila holds a PhD degree in information and knowledge management from Tampere University of Technology (TUT, 2015). Currently he acts as a principal research scientist at Häme University of Applied Sciences (HAMK). His research is currently focused on knowledge management, business intelligence, social media, big social data analytics, and health informatics. His work has been published in international journals such as IEEE Access, Computers in Human Behavior, Industrial Management \& Data Systems, the International Journal of Knowledge Management and Knowledge Management Research \& Practice.

Atte Partanen holds a bachelor's degree in electrical and automation engineering from Häme University of Applied Sciences (HAMK, 2017). He works as a project engineer in many projects focused on the Internet of Things, data management and information systems at Häme University of Applied Sciences (HAMK). His research is currently focused on information and data management systems. His work on information systems and smart cities has been published in journals.

Igor Trotskii graduated from Häme University of Applied Sciences with a degree in electrical and automation engineering. He works as a project engineer with responsibilities in data analysis, and the design and implementation of data-driven applications.

Dr. Aki Laiho holds a PhD degree from the Faculty of Industrial Engineering of Aalto University. $\mathrm{He}$ is a partner at Rolan Oy, which operates and maintains a shared-mobility vehicle fleet. 


\section{TIM Technology Innovation Management Review

\section{Academic Affiliations and Funding Acknowledgements}
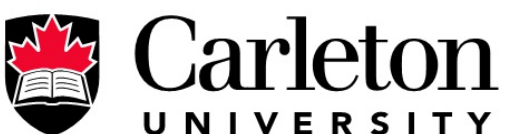
U N I V E R S I T Y

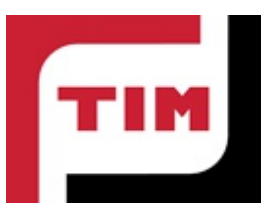

Technology Innovation Management (TIM; timprogram.ca) is an international master's level program at Carleton University in Ottawa, Canada. It leads to a Master of Applied Science (M.A.Sc.) degree, a Master of Engineering (M.Eng.) degree, or a Master of Entrepreneurship (M.Ent.) degree. The objective of this program is to train aspiring entrepreneurs on creating wealth at the early stages of company or opportunity lifecycles.

The TIM Review is published in association with and receives partial funding from the TIM program.

The TIM Review team is a key partner and contributor to the Scale Early, Rapidly and Securely (SERS) Project: https://globalgers.org/. Scale Early, Rapidly and Securely (SERS) is a global community actively collaborating to advance and disseminate high-quality educational resources to scale companies.

The SERS community contributes to, and leverages the resources of, the TIM Review (timreview.ca). The authors, readers and reviewers of the TIM Review worldwide contribute to the SERS project. Carleton University's Technology Innovation Management (TIM) launched the SERS Project in 2019.

We are currently engaged in a project focusing on identifying research and knowledge gaps related to how to scale companies. We are inviting international scholars to join the team and work on shaping Calls for Papers in the TIM Review addressing research and knowledge gaps that highly relevant to both academics and practitioners. Please contact the Editor-inChief, Dr. Stoyan Tanev (stoyan.tanev@carleton.ca) if you want to become part of this international open source knowledge development project. 